\title{
Respiratory Responses to Intravenous Infusion of Sodium Lactate in Male and Female Wistar Rats
}

\author{
Marie Olsson, M.Ph., Hoi-Por Ho, M.Sc., Kristina Annerbrink, B.M., Joakim Thylefors, M.D., and \\ Elias Eriksson, Ph.D.
}

In patients with panic disorder or premenstrual dysphoria, anxiety attacks can be triggered by intravenous administration of sodium lactate. Since respiratory symptoms, such as hyperventilation and shortness of breath, are characteristic features of spontaneous as well as lactate-induced panic, an involvement of central or peripheral chemoreceptors in this reaction has been suggested. In the present study, we examined to what extent intravenous infusion of sodium lactate influences respiratory parameters in freely moving male and female Wistar rats. Prompted by clinical reports suggesting that the susceptibility to spontaneous and lactate-induced anxiety may be influenced by the menstrual cycle, we also investigated if the effect of lactate on respiration in female rats is estrus cycle-dependent. Male and ovariectomized female rats exposed to sodium lactate displayed a larger increase in respiratory rate than rats given an infusion of saline. In intact female rats, the response to lactate infusion was significantly more pronounced in the diestrus phase than in the proestrus/estrus phase of the cycle. It is concluded that sodium lactate is a respiratory stimulant in rat, and that this effect is influenced by female sex steroids. [Neuropsychopharmacology 27:85-91, 2002] (C) 2002 American College of Neuropsychopharmacology. Published by Elsevier Science Inc.
KEY WORDS: Sodium lactate; Hyperventilation; Anxiety; Panic disorder; Premenstrual dysphoria; Estrus cycle; Rat

In patients with panic disorder (Liebowitz et al. 1984, 1985; Pitts and McClure 1967) or premenstrual dysphoria (Facchinetti et al. 1992; Sandberg et al. 1993), but not in healthy controls, intravenous (i.v.) administration of sodium lactate elicits an anxiety reaction strongly re-

From the Department of Pharmacology, Göteborg University Box 431, SE 40530 Göteborg, Sweden.

Address correspondence to: Marie Olsson, Department of Pharmacology, Göteborg University Box 431, SE 40530 Göteborg, Sweden. Tel.: +46 3177334 48; Fax: +46 318210 85; E-mail: marie. olsson@pharm.gu.se

Received April 27, 2001; revised January 15, 2002; accepted January 21, 2002.

Online publication: $1 / 22 / 02$ at www.acnp.org/citations/ Npp012202232. sembling spontaneous panic attacks. The anxiogenic effect of sodium lactate has been attributed to changes in calcium concentrations (Pitts and McClure 1967), $\mathrm{pH}$ (Grosz and Farmer 1972), redox activity (Carr et al. 1986), $\mathrm{pCO}_{2}$ (Gorman et al. 1988a), and osmolarity (Jensen et al. 1991; Peskind et al. 1998). However, all these theories and findings have also been questioned, and the mechanism by which sodium lactate elicits panic attacks hence is as yet unexplained.

Likewise, the reason why patients with panic disorder or premenstrual dysphoria differ from controls with respect to sensitivity to lactate is a matter of controversy. Notably, a more rapid and substantial rise in brain lactate has been observed in panic patients as compared with control subjects (Dager et al. 1999), but the difference between patients and controls may also be due to different responsiveness to a given concentration 
of lactate. Treatment with anti-panic medication usually prevents not only spontaneous but also lactate-induced panic attacks (Pohl et al. 1994; Rifkin et al. 1981).

Panic attacks are almost always associated with hyperventilation and respiratory discomfort, such as shortness of breath; it has thus been suggested that lactate-induced as well as spontaneous panic attacks may be due to an activation of a hyperresponsive suffocation alarm system involving activation of central or peripheral chemoreceptors (Klein 1993). Supporting this concept, an anxiety-provoking effect similar to that of lactate has been observed after inhalation of $\mathrm{CO}_{2}$ in panic disorder subjects and in women with premenstrual dysphoria (Gorman et al. 1984, 1988a, 2001; Griez et al. 1987; Harrison et al. 1989; Kent et al. 2001; Papp et al. 1997; Perna et al. 1994; Woods et al. 1986).

We have previously reported that intravenous administration of sodium lactate to Wistar rats, but not to rats of the Sprague-Dawley strain, elicits an increase in blood pressure and variable effects on heart rate (Wikander et al. 1995). Such cardiovascular response is in line with the assumption that lactate induces a stimulation of central or peripheral chemoreceptors. In the present study, the effect of sodium lactate on respiratory rate and tidal volume in freely moving, unrestrained male and female rats of the Wistar strain was explored. Given the previous reports suggesting that spontaneous panic attacks are menstrual cycle-dependent (Basoglu et al. 2000; Breier et al. 1986; Cameron et al. 1988; Cook et al. 1990; Klein 1993), that panic disorder may improve during pregnancy (Hertzberg and Wahlbeck 1999; Klein et al. 1994; Villeponteaux et al. 1992), and that patients with premenstrual dysphoria experience panic attacks when exposed to lactate (Facchinetti et al. 1992; Sandberg et al. 1993), we also investigated if possible effects of lactate on respiration are estrus cycle-dependent.

\section{MATERIALS AND METHODS}

\section{Animals}

Wistar rats (250-300 g), purchased from B\&K (Sollentuna, Sweden), were used. Before the experiments, the rats were housed with five animals per cage under controlled conditions: temperature $21-22^{\circ} \mathrm{C}$, humidity 55 $65 \%$. In experiment 1 , the rats were housed under normal 12/12 h dark/light cycle (lights on from 8 A.M. to 8 P.M.); in experiments 2 and 3, the dark/light cycle was reversed. In the second experiment, gonadectomized female rats were used; the ovariectomy was undertaken during anesthesia (mixture of ketamine $65 \mathrm{mg} / \mathrm{kg}$, Parke-Davis Scandinavia AB, Solna, Sweden, and xylazine $15 \mathrm{mg} / \mathrm{kg}$, Bayer AG, Leverkusen, Germany) at least 6 weeks before the acute experiments. In the third experiment, intact female rats were used, and tested in different phases of the estrus cycle. Cycle phases (metestrus, diestrus, proestrus/estrus) were determined by microscopical examination of vaginal smears in combination with tests of the estrus behavior (hop/darting, ear wiggling, lordosis), as assessed by placing the female rat in a cage inhabited by two male rats that were prevented from penile insertions. The lactate infusion experiments were undertaken in the diestrus and proestrus/estrus phases.

The study was carried out in accordance with the Guide for the Care and Use of Laboratory Animals as adopted and promulgated by the NIH and was approved by the Ethics Committee for Animal Experiments, Göteborg University, Sweden.

\section{Respiration Experiments}

One to three days before the acute experiment, an intravenous cannula was implanted in vena jugularis during anesthesia (mixture of ketamine $65 \mathrm{mg} / \mathrm{kg}$, Parke-Davis Scandinavia AB, Solna, Sweden, and xylazine $15 \mathrm{mg} /$ $\mathrm{kg}$, Bayer AG, Leverkusen, Germany). At the day of the acute experiment, the rat was put in a closed Plexiglas plethysmograph in which it could move freely. The breathing of the rat was reflected by oscillations in the pressure of the chamber, measured using a transducer and a Macintosh computer (software: MacLab). After the recording of baseline respiratory rate for at least 15 $\mathrm{min}$, an intravenous infusion of racemic sodium DL-lactate (Sigma-Aldrich Sweden $\mathrm{AB})(0.5 \mathrm{M}$ or $2 \mathrm{M})$ or a physiological $\mathrm{NaCl}$ solution $(0.9 \mathrm{M})$ (saline) was started. Flow rate was $0.5 \mathrm{ml} / \mathrm{kg} / \mathrm{min}$ and the infusion lasted for $5 \mathrm{~min}$ and $20 \mathrm{~s}$. The differences between baseline respiratory rate (mean of the 2 min preceding start of the infusion) and the maximal respiratory rate during infusion (defined as the 2 min with the highest mean) were used as a measure of lactate- or saline-induced change in respiratory rate. In addition to respiratory rate, also tidal volume and minute volume were registered. These volume data are presented as change from baseline levels, and are those recorded during the same 2-min period as used for assessment of respiratory rate (see above).

\section{Statistics}

Differences between groups were statistically evaluated using ANOVA followed by Fischer's PLSD test. All group values are given as mean $\pm \mathrm{SD}$.

\section{RESULTS}

\section{Experiment 1}

Male rats administered sodium lactate $0.5 \mathrm{M}(\mathrm{n}=8)$ or $2 \mathrm{M}(\mathrm{n}=7)$ displayed a significantly greater increase in respiratory rate than rats given a saline infusion $(n=9)$ 
(ANOVA: $\mathrm{F}=14.3, \mathrm{DF}=2 / 21, p=.0001$ ) (Figure 1, panel A). The increase in respiratory rate usually reached a maximum within 2-3 min after the onset of the infusion; when the infusion was stopped, respiratory rate normally returned to baseline levels within a minute. The ANOVA comparing all three groups with respect to change in tidal volume revealed a significant difference $(\mathrm{F}=5.5, \mathrm{DF}=2 / 21, p=.01)$; in the subsequent post-hoc test, rats receiving lactate $0.5 \mathrm{M}$, but not those receiving $2 \mathrm{M}$, were found to display lower tidal volume than those given saline (Figure 1, panel B). The minute volume also was significantly influenced by lac-
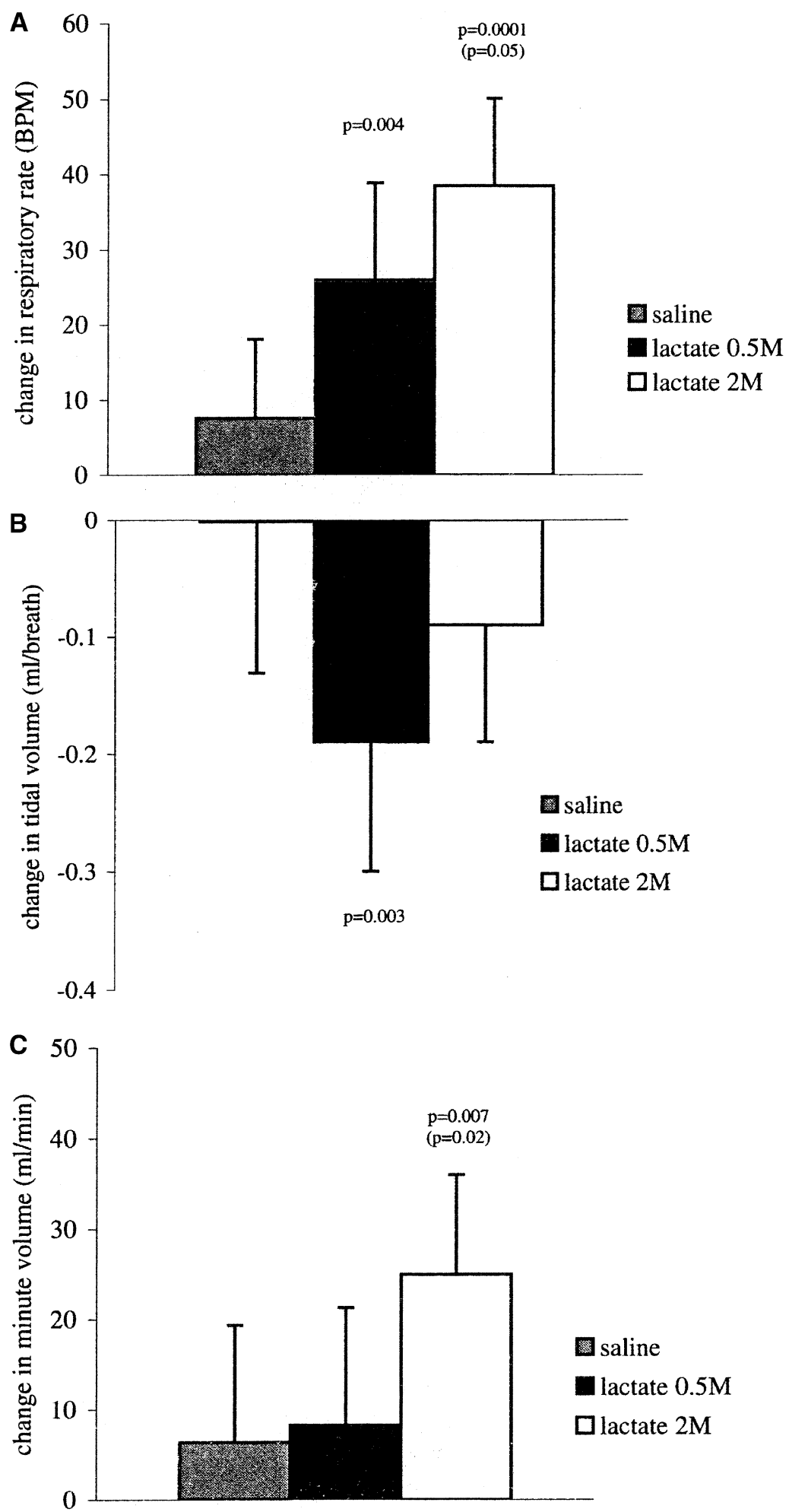

saline

lactate $0.5 \mathrm{M}$

lactate $2 \mathrm{M}$
Figure 1. Effect of i.v. infusion of sodium lactate (0.5 M; $2 \mathrm{M})$ ( $\mathrm{n}=8$ and 7 , respectively) and saline $(n=9)$ on respiration in male Wistar rats. Baseline respiratory rate (breaths per minute \pm SD) (0.5 M: $91.9 \pm 20.6,2$ M: $98.9 \pm 14.9$, saline: $92.5 \pm 8.8$ ), tidal volume (data not shown), and minute volume (data not shown) did not differ between groups. Bars represent mean ( \pm SD) change from baseline values. $p$ values refer to differences versus saline, except $p$ values in brackets, which refer to differences versus $0.5 \mathrm{M}$ lactate (ANOVA followed by Fisher's PLSD). Panel A: Effect of lactate on respiratory rate (breaths per minute). Panel B: Effect of lactate on tidal volume (ml/breath) Panel C: Effect of lactate on minute volume $(\mathrm{ml} / \mathrm{min})$. 
tate (ANOVA: $\mathrm{F}=5.2, \mathrm{DF}=2 / 21, p=.02$ ); the subsequent analyses revealed that it was increased in rats receiving lactate $2 \mathrm{M}$, but unchanged in those receiving lactate $0.5 \mathrm{M}$ (Figure 1, panel C).

\section{Experiment 2}

Infusion of sodium lactate $2 \mathrm{M}$ to ovariectomized female rats $(n=13)$ caused a greater increase in respiratory rate than infusion of saline $(\mathrm{n}=9)$; in contrast, rats receiving infusion of $0.5 \mathrm{M}$ sodium lactate did not differ from those given saline (data not shown). Whereas the ANOVA comparing all three groups was not significant $(\mathrm{F}=1.8, \mathrm{DF}=3 / 25, p=.2)$, a comparison of lactate $2 \mathrm{M}$ and saline revealed a significant difference (Figure 2). Tidal volume was moderately reduced in rats receiving lactate $0.5 \mathrm{M}$ as compared with controls, but not in those receiving lactate $2 \mathrm{M}$; neither this difference nor the difference in minute volume however reached statistical significance (data not shown).

\section{Experiment 3}

Intact female rats studied in the nonreceptive phase (diestrus) $(n=8)$ did not differ from those studied in the receptive phase (proestrus/estrus) $(n=10)$ of the estrus cycle with respect to baseline respiratory rate (legend to Figure 3), tidal volume (data not shown), or minute volume (data not shown). The increase in respiratory rate after infusion of sodium lactate was however significantly higher in the nonreceptive phase (diestrus) $(\mathrm{n}=8)$ than in the receptive phase (proestrus/ estrus) $(n=10)$ of the estrus cycle (Figure 3 ). Moreover, the respiratory rate in intact female rats studied in the diestrus phase was found to be larger than the response previously (=experiment 2 ) observed in ovariectomized animals $(p=.01)$ (ANOVA followed by Fisher's PLSD); in contrast, the response in the proestrus/estrus phase did not differ significantly from that of gonadectomized animals $(p=1)$ (ANOVA followed by Fisher's PLSD). Notably, since intact and ovariectomized animals were studied in different experiments, these comparisons should be interpreted with caution.

In neither cycle phase, tidal volume was significantly influenced by the infusion (data not shown). The increase in minute volume observed during lactate infusion was significantly higher in rats studied in the diestrus phase than in those studied in the estrus phase of the cycle (ANOVA: $\mathrm{F}=5.2, \mathrm{DF}=1 / 16, p=.04$ ) (data not shown).

\section{DISCUSSION}

Several authors have suggested that peripheral and/or central chemoreceptors are involved in the anxiogenic effects of lactate. Supporting this assumption, lactateinduced panic is associated with hyperventilation (Gorman 1988b; Klein 1993); moreover, in panic disorder patients, as well as in patients with premenstrual dysphoria, panic attacks can be elicited not only by sodium lactate, but also by $\mathrm{CO}_{2}$ exposure (Gorman et al. 1988a, 2001; Griez et al. 1987; Harrison et al. 1989; Kent et al. 2001; Papp et al. 1997; Perna et al. 1994; Woods et al. 1986).

The hyperventilation observed in rats exposed to intravenous infusion of sodium lactate supports the concept that lactate may induce an activation of peripheral and/or central chemoreceptors; also, it suggests that one mechanism that is probably involved in lactateinduced panic anxiety may be investigated in experimental animals. However, the results obtained in our experiments contrast to previous publications of Shekhar and co-workers (Shekhar and Keim 1997, 2000; Shekhar et al. 1996) reporting no effects of a $0.5 \mathrm{M}$ lactate solution on cardiovascular and respiratory parameters in intact rats of the Sprague-Dawley strain. We

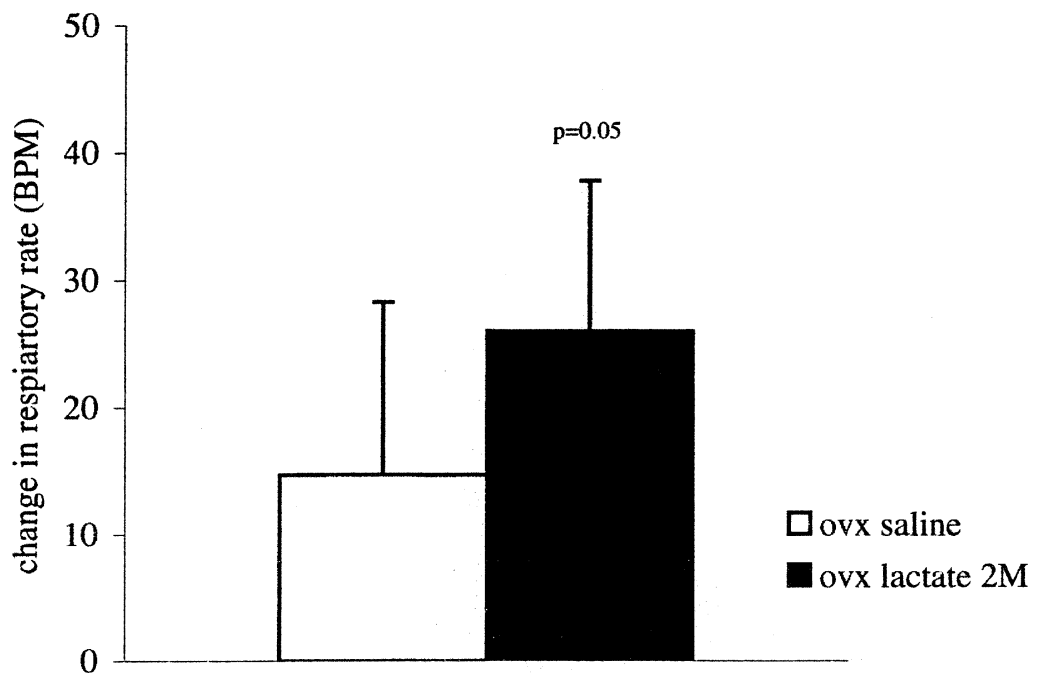

Figure 2. Effect of i.v. infusion of sodium lactate $(2 M)(n=13)$ and saline $(n=9)$ on respiratory rate (breaths per minute) in female ovariectomized (ovx) Wistar rats. Bars represent mean ( $\pm \mathrm{SD}$ ) change from baseline respiratory rate. $p$ value refers to difference versus saline (ANOVA followed by Fisher's PLSD). Baseline respiratory rate (breaths per minute \pm SD) did not differ between groups (2 M: $78.9 \pm 8.2$, saline: $88.6 \pm 14.4$ ). 


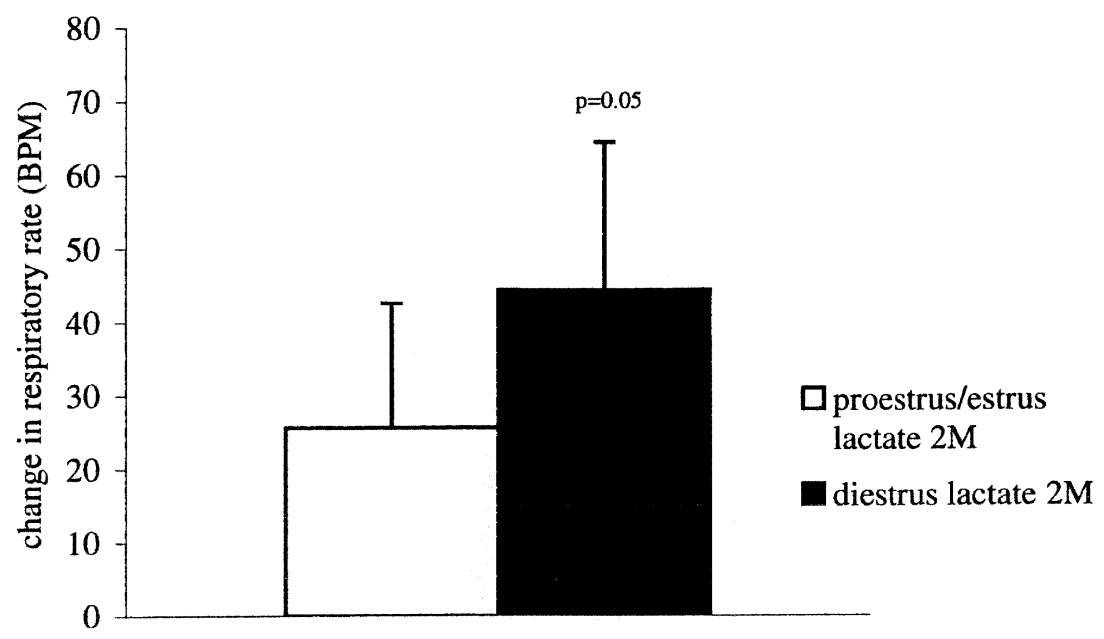

Figure 3. Effect of i.v. infusion of saline or sodium lactate $(2 \mathrm{M})$ on respiratory rate (breaths per minute) in intact female Wistar rats tested in the diestrus $(n=8)$ or proestrus/estrus $(n=10)$ phase of the cycle. Bars represent mean $( \pm \mathrm{SD})$ change from baseline respiratory rate. $p$ value refers to difference versus proestrus/estrus (ANOVA followed by Fisher's PLSD). Baseline respiratory rate (breaths per minute \pm SD) did not differ between groups (diestrus: $88.8 \pm 11.9$; proestrus/estrus: $84.1 \pm 16.9$ ).

have previously shown that the cardiovascular response to lactate is more pronounced in Wistar rats than in Sprague-Dawley rats (Wikander et al. 1995); tentatively, the difference between our results and those of Shekhar and co-workers with respect to effects of lactate on respiration could thus be due to the use of different strains. Previous literature does support the notion that rats of Wistar strains (including Wistar-Kyoto) and Sprague-Dawley rats differ with respect to various aspects of behavior, (Galan et al. 1994; LopezRubalcava and Lucki 2000; Pilz et al. 1999; Shoaib et al. 1995) and also that chemoreceptor responsiveness may be higher in Wistar-Kyoto rats than in rats of the Sprague-Dawley strain (Hayward et al. 1999).

In most clinical experiments, $10 \mathrm{ml}$ of $0.5 \mathrm{M}$ lactate solution have been given for a period of $20 \mathrm{~min}$; the flow rate hence has been the same as in our animal experiments $(0.5 \mathrm{ml} / \mathrm{kg} / \mathrm{min})$. Since the maximal respiratory response to lactate in rat was usually observed already within the first 5 min of infusion, it was decided to stop the infusion after $5 \mathrm{~min} 20 \mathrm{~s}$; the total amount of lactate solution administered has hence been less in our animal experiments than in most clinical studies. It has been reported that lactate is metabolized more rapidly in rat than in man (Freminet and Leclerc 1979; Searle et al. 1989); therefore lactate concentration achieved in the brain are probably lower in rats than in humans given the corresponding amount of lactate. To compensate for the shorter period of infusion applied in the rat experiments as compared with clinical studies, and for the fact that the metabolism of lactate seems more rapid in rat than in man, not only the effects of the same lactate concentrations as are used in clinical studies $(0.5 \mathrm{M})$ were tested, but also those of a higher concentration (2 M).

In spite of causing an increase in respiratory rate, the $0.5 \mathrm{M}$ lactate concentration did not increase minute volume, since the increase in frequency was associated with a reduction in tidal volume. In contrast, the higher concentration of lactate $(2 \mathrm{M})$ led to an increase in respi- ratory rate without a concomitant reduction of tidal volume, the net effect being a substantial increase in minute volume. Likewise, we have recently observed that exposure of Wistar rats in the same experimental paradigm to low concentrations of $\mathrm{CO}_{2}(1.5 \%)$ leads to an increase in respiratory rate but to a reduction in tidal volume, whereas higher concentrations of $\mathrm{CO}_{2}(6 \%)$ leads to an increase in respiratory rate with no reduction in tidal volume. Given the fact that lactate infusion has been reported to cause a substantial increase in minute volume, in humans (Gorman et al. 1988b), it may be argued that the rat experiments using a $2 \mathrm{M}$ solution perhaps more faithfully reflects the clinical lactate provocation test than those using a lactate concentration of $0.5 \mathrm{M}$. Also, it should be underlined that both lactate-induced (Gorman et al. 1988b), and spontaneous (Martinez et al. 1996) panic attacks in man are associated with an increase in tidal volume that appears to be even more pronounced than the increase in respiratory rate.

Lactate infusions are known to induce metabolic alkalosis, which could be expected to lead to a reduction in minute volume rather than to an increase in respiration. However, the notion of lactate nevertheless being a respiratory stimulant gains support from previous clinical studies reporting lactate to enhance respiration, not only in panic disorder patients but also in normal controls (Gorman et al. 1988b). If the respiratory stimulation induced by lactate is due to a direct activation of chemoreceptors or to some other mode of action is as yet unknown, but the fact that it can be studied in experimental animals hopefully will increase the possibilities to elucidate the underlying mechanisms.

The rapid normalization of breathing after lactate infusion contrasts to what has previously been reported in patients with panic disorder. Differences in the duration of the infusion, or differences between rat and man with respect to the half-life of lactate (see above), may explain this discrepancy. It is also not unlikely that the respiratory response observed in rats is due merely to a 
direct influence of lactate on chemoreceptors or related structures, whereas the respiratory response to lactate in panic disorder patients may be due to the combined effect of a direct stimulatory effect of lactate on respiration, corresponding to that observed in Wistar rats, and to an increase in respiration secondary to the panic reaction elicited.

Previous reports suggest a premenstrual exacerbation of panic disorder (Basoglu et al. 2000; Breier et al. 1986; Cameron et al. 1988; Cook et al. 1990; Klein 1993; however, see also Stein et al. 1989), that panic disorder may improve during pregnancy (Hertzberg and Wahlbeck 1999; Klein et al. 1994; Villeponteaux et al. 1992), and that patients with premenstrual dysphoria experience panic attacks when exposed to lactate (Facchinetti et al. 1992; Sandberg et al. 1993, see also Yonkers 1997). Given the possible influence of female sex steroids on the respiratory effect of lactate, in the first experiment using female rats (experiment 2), the animals were gonadectomized before being tested in order to avoid the possible influence of estrus cyclicity. In the second experiment using female rats (experiment 3 ), intact animals were used, and tested in different phases of the estrus cycle. The observation that the respiratory response to lactate was more pronounced in the nonreceptive phase (diestrus) than in the receptive phase (proestrus / estrus), and also more pronounced in intact animals studied in the diestrus phase than in ovariectomized rats, supports an influence of female sex steroids in this context. Given the apparent relationship between panic disorder and premenstrual dysphoria, it is noteworthy that the phase of the estrus cycle in which the respiratory response to lactate was most pronounced is also the phase of the cycle when Wistar rats display irritability and aggression in a putative animal model of premenstrual dysphoria (Ho et al. 2001).

It seems likely that a revelation of the precise mechanisms of action involved in lactate-induced anxiety attacks will increase our understanding of the biology of panic disorder. The present study does not demonstrate why patients with panic disorder or premenstrual dysphoria get anxiety attacks from lactate infusion, but it does support the hypothesis that lactate is a respiratory stimulant, and it indicates that animal studies may be of value in elucidating at least parts of the chain of events triggered by lactate infusion and leading to a panic attack. Finally, our data suggest that lactate-induced hyperventilation in female rats is estrus cycle-dependent.

\section{ACKNOWLEDGMENTS}

This study was sponsored by the Swedish Medical Research Council (grant no. 8668), Fredrik and Ingrid Thuring's Foundation, Knut and Alice Wallenberg's Foundation, AstraZeneca, and the Swedish Lundbeck Foundation. Ms. Inger Os- carsson and Ms. Gunilla Bourghardt provided excellent technical assistance.

\section{REFERENCES}

Basoglu C, Cetin M, Semiz UB, Agargun MY, Ebrinc S (2000): Premenstrual exacerbation and suicidal behavior in patients with panic disorder. Compr Psychiatry 41:103-105

Breier A, Charney DS, Heninger GR (1986): Agoraphobia with panic attacks. Development, diagnostic stability, and course of illness. Arch Gen Psychiatry 43:1029-1036

Cameron OG, Kuttesch D, McPhee K, Curtis GC (1988): Menstrual fluctuation in the symptoms of panic anxiety. J Affect Disord 15:169-174

Carr DB, Sheehan DV, Surman OS, Coleman JH, Greenblatt DJ, Heninger GR, Jones KJ, Levine PH, Watkins WD (1986): Neuroendocrine correlates of lactate-induced anxiety and their response to chronic alprazolam therapy. Am J Psychiatry 143:483-494

Cook BL, Noyes R Jr, Garvey MJ, Beach V, Sobotka J, Chaudhry D (1990): Anxiety and the menstrual cycle in panic disorder. J Affect Disord 19:221-226

Dager SR, Friedman SD, Heide A, Layton ME, Richards T, Artru A, Strauss W, Hayes C, Posse S (1999): Twodimensional proton echo-planar spectroscopic imaging of brain metabolic changes during lactate-induced panic. Arch Gen Psychiatry 56:70-77

Facchinetti F, Romano G, Fava M, Genazzani AR (1992): Lactate infusion induces panic attacks in patients with premenstrual syndrome. Psychosom Med 54:288-296

Freminet A, Leclerc L (1979): Lactate kinetics estimated by single injection and continuous infusion of [14C-(U)]lactate in rats. J Physiol 75:555-557

Galan X, Llobera M, Ramirez I (1994): Lipoprotein lipase and hepatic lipase in Wistar and Sprague-Dawley rat tissues. Differences in the effects of gender and fasting. Lipids 29:333-336

Gorman JM, Askanazi J, Liebowitz MR, Fyer AJ, Stein J, Kinney JM, Klein DF (1984): Response to hyperventilation in a group of patients with panic disorder. Am J Psychiatry 141:857-861

Gorman JM, Fyer MR, Goetz R, Askanazi J, Liebowitz MR, Fyer AJ, Kinney J, Klein DF (1988a): Ventilatory physiology of patients with panic disorder. Arch Gen Psychiatry 45:31-39

Gorman JM, Goetz RR, Uy J, Ross D, Martinez J, Fyer AJ, Liebowitz MR, Klein DF (1988b): Hyperventilation occurs during lactate-induced panic. J Anxiety Disord 2:193-202

Gorman JM, Kent J, Martinez J, Browne S, Coplan J, Papp LA (2001): Physiological changes during carbon dioxide inhalation in patients with panic disorder, major depression, and premenstrual dysphoric disorder: evidence for a central fear mechanism. Arch Gen Psychiatry 58:125-131

Griez EJ, Lousberg H, van den Hout MA, van der Molen GM (1987): CO2 vulnerability in panic disorder. Psychiatry Res 20:87-95 
Grosz HJ, Farmer BB (1972): Pitts' and McClure's lactateanxiety study revisited. Br J Psychiatry 120:415-418

Harrison WM, Sandberg D, Gorman JM, Fyer M, Nee J, Uy J, Endicott J (1989): Provocation of panic with carbon dioxide inhalation in patients with premenstrual dysphoria. Psychiatry Res 27:183-192

Hayward LF, Johnson AK, Felder RB (1999): Arterial chemoreflex in conscious normotensive and hypertensive adult rats. Am J Physiol 276:H1215-H1222

Hertzberg T, Wahlbeck K (1999): The impact of pregnancy and puerperium on panic disorder: a review. J Psychosom Obstet Gynaecol 20:59-64

Ho H-P, Olsson M, Westberg L, Melke J, Eriksson E (2001): The serotonin reuptake inhibitor fluoxetine reduces sex steroid-related aggression in female rats: An animal model of premenstrual irritability? Neuropsychopharmacology 24:502-510

Jensen CF, Peskind ER, Veith RC, Hughes J, Cowley DS, Roy-Byrne P, Raskind MA (1991): Hypertonic saline infusion induces panic in patients with panic disorder. Biol Psychiatry 30:628-630

Kent JM, Papp LA, Martinez JM, Browne ST, Coplan JD, Klein DF, Gorman JM (2001): Specificity of panic response to $\mathrm{CO}(2)$ inhalation in panic disorder: a comparison with major depression and premenstrual dysphoric disorder. Am J Psychiatry 158:58-67

Klein DF (1993): False suffocation alarms, spontaneous panics, and related conditions. An integrative hypothesis. Arch Gen Psychiatry 50:306-317

Klein DF, Skrobala AM, Garfinkel RS (1994): Preliminary look at the effects of pregnancy on the course of panic disorder. Anxiety 1:227-232

Liebowitz MR, Fyer AJ, Gorman JM, Dillon D, Appleby IL, Levy G, Anderson S, Levitt M, Palij M, Davies SO, Klein DF (1984): Lactate provocation of panic attacks. I. Clinical and behavioral findings. Arch Gen Psychiatry 41:764-770

Liebowitz MR, Gorman JM, Fyer AJ, Levitt M, Dillon D, Levy G, Appleby IL, Anderson S, Palij M, Davies SO, Klein DF (1985): Lactate provocation of panic attacks. II. Biochemical and physiological findings. Arch Gen Psychiatry 42:709-719

Lopez-Rubalcava C, Lucki I (2000): Strain differences in the behavioral effects of antidepressant drugs in the rat forced swimming test. Neuropsychopharmacology 22:191-199

Martinez JM, Papp LA, Coplan JD, Anderson DE, Mueller CM, Klein DF, Gorman JM (1996): Ambulatory monitoring of respiration in anxiety. Anxiety 2:296-302

Papp LA, Martinez JM, Klein DF, Coplan JD, Norman RG, Cole R, de Jesus MJ, Ross D, Goetz R, Gorman JM (1997): Respiratory psychophysiology of panic disorder: three respiratory challenges in 98 subjects. Am J Psychiatry 154:1557-1565

Perna G, Battaglia M, Garberi A, Arancio C, Bertani A, Bellodi L (1994): Carbon dioxide/oxygen challenge test in panic disorder. Psychiatry Res 52:159-171

Peskind ER, Jensen CF, Pascualy M, Tsuang D, Cowley D, Martin DC, Wilkinson CW, Raskind MA (1998): Sodium lactate and hypertonic sodium chloride induce equivalent panic incidence, panic symptoms, and hypernatremia in panic disorder. Biol Psychiatry 44:1007-1016

Pilz PK, Linke R, Yilmazer-Hanke DM, Schwegler H (1999): Comparison of two sensitization paradigms of the acoustic startle response in Wistar and Sprague-Dawley rats. Behav Genet 29:59-63

Pitts FN Jr, McClure JN Jr (1967): Lactate metabolism in anxiety neurosis. N Engl J Med 277:1329-1336

Pohl R, Balon R, Berchou R, Lycaki H (1994): Lactateinduced anxiety after imipramine and diazepam treatment. Anxiety 1:54-63

Rifkin A, Klein DF, Dillon D, Levitt M (1981): Blockade by imipramine or desipramine of panic induced by sodium lactate. Am J Psychiatry 138:676-677

Sandberg D, Endicott J, Harrison W, Nee J, Gorman J (1993): Sodium lactate infusion in late luteal phase dysphoric disorder. Psychiatry Res 46:79-88

Searle GL, Feingold KR, Hsu FS, Clark OH, Gertz EW, Stanley WC (1989): Inhibition of endogenous lactate turnover with lactate infusion in humans. Metabolism 38:1120-1123

Shekhar A, Keim SR (1997): The circumventricular organs form a potential neural pathway for lactate sensitivity: implications for panic disorder. J Neurosci 17:9726-9735

Shekhar A, Keim SR (2000): LY354740, a potent group II metabotropic glutamate receptor agonist prevents lactate-induced panic-like response in panic-prone rats. Neuropharmacology 39:1139-1146

Shekhar A, Keim SR, Simon JR, McBride WJ (1996): Dorsomedial hypothalamic GABA dysfunction produces physiological arousal following sodium lactate infusions. Pharmacol Biochem Behav 55:249-256

Shoaib M, Spanagel R, Stohr T, Shippenberg TS (1995): Strain differences in the rewarding and dopamine-releasing effects of morphine in rats. Psychopharmacology (Berl) 117:240-247

Stein MB, Schmidt PJ, Rubinow DR, Uhde TW (1989): Panic disorder and the menstrual cycle: panic disorder patients, healthy control subjects, and patients with premenstrual syndrome. Am J Psychiatry 146:1299-1303

Villeponteaux VA, Lydiard RB, Laraia MT, Stuart GW, Ballenger JC (1992): The effects of pregnancy on preexisting panic disorder. J Clin Psychiatry 53:201-203

Wikander I, Roos T, Stakkestad A, Eriksson E (1995): Sodium lactate elicits a rapid increase in blood pressure in Wistar rats and spontaneously hypertensive rats. Effect of pretreatment with the antipanic drugs clomipramine and alprazolam. Neuropsychopharmacology $12: 245-250$

Woods SW, Charney DS, Loke J, Goodman WK, Redmond DE Jr, Heninger GR (1986): Carbon dioxide sensitivity in panic anxiety. Ventilatory and anxiogenic response to carbon dioxide in healthy subjects and patients with panic anxiety before and after alprazolam treatment. Arch Gen Psychiatry 43:900-909

Yonkers KA (1997): Anxiety symptoms and anxiety disorders: how are they related to premenstrual disorders? J Clin Psychiatry 58: 62-69 